\title{
Encephaloduroarteriosynangiosis and encephalomyoarteriosynangiosis for treatment of moyamoya syndrome in pediatric patients with sickle cell disease
}

\author{
Christoph J. Griessenauer, MD, ${ }^{1}$ Jeffrey D. Lebensburger, DO, ${ }^{2}$ Michelle H. Chua, BS, ${ }^{3}$ \\ Winfield S. Fisher III, MD, ${ }^{1}$ Lee Hilliard, MD, ${ }^{2}$ Christina J. Bemrich-Stolz, MD, MSPH, ${ }^{2}$ \\ Thomas H. Howard, MD, ${ }^{2}$ and James M. Johnston, MD'
}

Departments of ${ }^{1}$ Neurosurgery and ${ }^{2}$ Pediatric Hematology Oncology, University of Alabama at Birmingham, Alabama; and ${ }^{3}$ Harvard Medical School, Boston, Massachusetts

\begin{abstract}
OBJECT Pediatric patients with sickle cell disease (SCD) and moyamoya syndrome (MMS) are at significant risk for cerebrovascular accidents despite chronic transfusion therapy. Encephaloduroarteriosynangiosis (EDAS) and encephalomyoarteriosynangiosis (EMAS) are additional therapeutic options for these patients. To date, the incidence of complications after and efficacy of EDAS and EMAS in stroke prevention in this population have been described in several institutional case series reports, but no randomized prospective trials have been reported.

METHODS The authors retrospectively reviewed the cases of all pediatric patients at the University of Alabama at

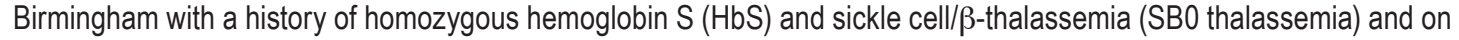
chronic transfusion therapy, including 14 patients with MMS who underwent EDAS or EMAS.

RESULTS Sixty-two patients with SCD and on chronic transfusion therapy were identified. After exclusion of patients on chronic transfusion therapy for indications other than stroke prevention, 48 patients $(77.4 \%)$ remained. Of those patients, $14(29.1 \%)$ underwent EDAS or EMAS. Nine (18.8\%) and $25(52.1 \%)$ patients were on chronic transfusion therapy for primary or secondary stroke prevention, respectively, but did not undergo EDAS or EMAS. The 14 patients with SCD and radiological evidence of MMS and on chronic transfusion therapy for primary or secondary stroke prevention underwent 21 EDAS or EMAS procedures for progressive vascular disease (92.9\% of patients), stroke (71.4\%), and/or seizure $(7.1 \%)$. The mean $( \pm S D)$ time from initiation of chronic transfusion therapy to EDAS or EMAS was $76.8 \pm 58.8$ months. Complications included 1 perioperative stroke, 1 symptomatic subdural hygroma, 1 postoperative seizure, and 1 case of intraoperative cerebral edema that required subsequent cranioplasty. Before EDAS or EMAS, the stroke rate was calculated to be 1 stroke per 7.8 patient-years. One additional stroke occurred during the follow-up period (mean follow-up time $33.7 \pm 19.6$ months), resulting in a post-EDAS/EMAS stroke rate of 1 stroke per 39.3 patient-years, a 5 -fold reduction compared with that in the pre-EDAS/EMAS period. The patients' mean pre-EDAS/EMAS HbS level of $29.5 \% \pm 6.4 \%$ was comparable to the mean post-EDAS/EMAS HbS level of $25.5 \% \pm 6.1 \%(p=0.104)$.
\end{abstract}

CONCLUSIONS The results of this retrospective case series in a large cohort of pediatric patients with SCD and MMS suggest that EDAS/EMAS provides a stroke-prevention benefit with an acceptably low morbidity rate. Given the combined experience with EDAS and EMAS for this indication at this and other institutions, a prospective clinical trial to assess their efficacy compared with that of chronic transfusion therapy alone is warranted.

http://thejns.org/doi/abs/10.3171/2014.12.PEDS14522

KEY WORDS moyamoya syndrome; sickle cell disease; vascular disorders

ABBREVIATIONS DSA = digital subtraction angiography; EDAS = encephaloduroarteriosynangiosis; EMAS = encephalomyoarteriosynangiosis; $\mathrm{Hb}=$ hemoglobin; HbS = hemoglobin S; ICA = internal carotid artery; MCA = middle cerebral artery; MMS = moyamoya syndrome; MRA = MR angiography; $S C D=$ sickle cell disease; $T C D=$ transcranial Doppler.

SUBMITTED September 30, 2014. ACCEPTED December 3, 2014.

INCLUDE WHEN CITING Published online April 3, 2015; DOI: 10.3171/2014.12.PEDS14522.

DISCLOSURE The authors report no conflict of interest concerning the materials or methods used in this study or the findings specified in this paper. 
$\mathrm{S}$ TROKE occurs in approximately $10 \%$ of patients with sickle cell disease (SCD) before the age of 20 years. Strokes in patients with SCD account for significant morbidity and death in this patient population and are mainly attributed to microvascular and macrovascular arteriopathies. Microvascular arteriopathy may be related to sickle cell adhesion, subsequent stasis, and vascular occlusion at the level of the arteriole, capillaries, and postcapillary venule and accounts for approximately $25 \%$ of strokes ${ }^{27}$ particularly in the susceptible deep white matter. ${ }^{28}$ Macrovascular arteriopathy is postulated to be responsible for approximately $75 \%$ of strokes ${ }^{27}$ and affects the more proximal cerebral circulation, where higher flow results in substantial shear stress on the walls of the arteries and turbulence at sites of bifurcation. Recurrent adhesion and release of sickle cells leads to endothelial injury followed by intimal hyperplasia and luminal stenosis. Injured arterial walls then promote thrombus formation and embolization. The progression from stenosis to occlusion of the supraclinoid internal cerebral and proximal anterior and middle cerebral arteries prompts the development of a collateral network of fragile small-caliber arteries arising from the lenticulostriate arteries that resembles a moyamoya pattern on arteriography. ${ }^{28}$ This so-called moyamoya syndrome (MMS) is present in $30 \%^{31}$ to $43 \%{ }^{13}$ of patients with SCD and history of stroke.

Chronic transfusion therapy is the mainstay for primary stroke prevention in patients with evidence of cerebrovascular compromise based on transcranial Doppler (TCD) criteria and for secondary stroke prevention in patients with a history of stroke. This approach, however, does not protect all patients, especially those with progressive cerebrovascular disease, and it is associated with complications such as iron overload and increased risk for stroke with noncompliance or discontinuation of therapy. ${ }^{7,8,19}$ Surgical revascularization procedures, including direct and indirect bypass procedures, have been proposed to increase blood delivery to the ischemic brain. Of the indirect bypass procedures, encephaloduroarteriosynangiosis (EDAS) and encephalomyoarteriosynangiosis (EMAS) with pial synangiosis are the most commonly used, and results from other centers have been reported. ${ }^{17,21,32}$ Here, we report our experience with EDAS/EMAS in 14 patients with SCD and MMS and compare these results with those in patients with SCD on chronic transfusion therapy who did not undergo EDAS/EMAS.

\section{Methods}

After approval from the University of Alabama at Birmingham institutional review board, the case of each pediatric patient with SCD (homozygous hemoglobin S $[\mathrm{HbS}]$ and sickle cell/ $\beta$-thalassemia [SB0 thalassemia]) and on chronic transfusion therapy between 2007 and 2014 at the University of Alabama at Birmingham and Children's of Alabama was reviewed retrospectively. A stroke was defined as the new onset of a neurological deficit with correlated ischemic findings on imaging, whereas silent ischemic events were defined as ischemic imaging findings that remained clinically silent. Per the institutional protocol for management of stroke prevention in pa- tients with SCD, a patient is started on chronic transfusion therapy for primary stroke prevention if a time-averaged mean blood flow velocity of $\geq 200 \mathrm{~cm} / \mathrm{sec}$ in the terminal internal carotid artery (ICA) or middle cerebral artery (MCA) is detected with TCD screening. ${ }^{2}$ Any patient who has had a stroke or a silent ischemic event receives chronic transfusion therapy (or hydroxyurea) for secondary stroke prevention (Fig. 1). The study included patients with MMS who underwent EDAS or EMAS. ${ }^{2}$ The diagnosis of MMS was based on cerebrovascular imaging (MR angiography [MRA], CT angiography, and/or digital subtraction angiography [DSA]) conducted at presentation in symptomatic patients. Patients with neurovascular symptoms (i.e., stroke, transient ischemic attack, or seizures) and patients with evidence of progressive vascular disease and ischemic changes as revealed by MRI/MRA were recommended for EDAS/EMAS. Before EDAS/EMAS, patients had scheduled MRI/MRA surveillance every 1 to 2 years. Per institutional preference, children with a history of stroke or a silent ischemic event were not treated with aspirin prophylaxis.

Demographic information and clinical, radiological, and hematological data were assessed. Hemoglobin $(\mathrm{Hb})$ and percentage $\mathrm{HbS}$ levels were obtained 1-3 days before every scheduled transfusion. For the patients receiving chronic transfusion therapy who did not undergo EDAS/ EMAS, $\mathrm{Hb}$ and $\mathrm{HbS}$ levels were recorded from the date on which chronic transfusion therapy was initiated to the last follow-up visit. For the patients who underwent EDAS or EMAS, $\mathrm{Hb}$ and $\mathrm{HbS}$ levels were recorded from the time of the first abnormal MRI result to the last follow-up visit. $\mathrm{Hb}$ and $\mathrm{HbS}$ levels are expressed as the mean and SD of all $\mathrm{Hb}$ and $\mathrm{HbS}$ levels recorded over the time on chronic transfusion therapy versus the pre- and post-EDAS/EMAS periods in patients who did not and did undergo EDAS/ EMAS, respectively.

\section{Perioperative and Postoperative Management After EDAS or EMAS}

Since 2011, all children undergoing EDAS/EMAS were admitted to the hospital the day before surgery for intravenous hydration to mitigate the risk of perioperative stroke and anesthesia-related complications. Transfusion therapy was given the day before the procedure with a goal $\mathrm{HbS}$ level of $<30 \%$ and a posttransfusion $\mathrm{Hb}$ level of at least $10 \mathrm{~g} / \mathrm{dl}$. In addition, each child underwent preoperative baseline electroencephalography and then was monitored intraoperatively with a limited montage. Each patient was noted to have at least 1 transient episode of intraoperative electroencephalographic slowing or decreased amplitude. A more detailed analysis of intraoperative electroencephalographic changes and utility of this information will be the subject of a future article. Episodes of electroencephalographic slowing or decreased amplitude during surgery were treated with elevation of mean arterial pressure and neuroprotective doses of propofol. Patients 1-6 underwent EMAS and Patients 7-14 underwent EDAS with pial synangiosis according to a method previously published by Adelson and Scott. ${ }^{4}$ Dural inversion was added to standard pial synangiosis in some children when feasible. All patients undergoing bilateral EDAS had staged operations. 


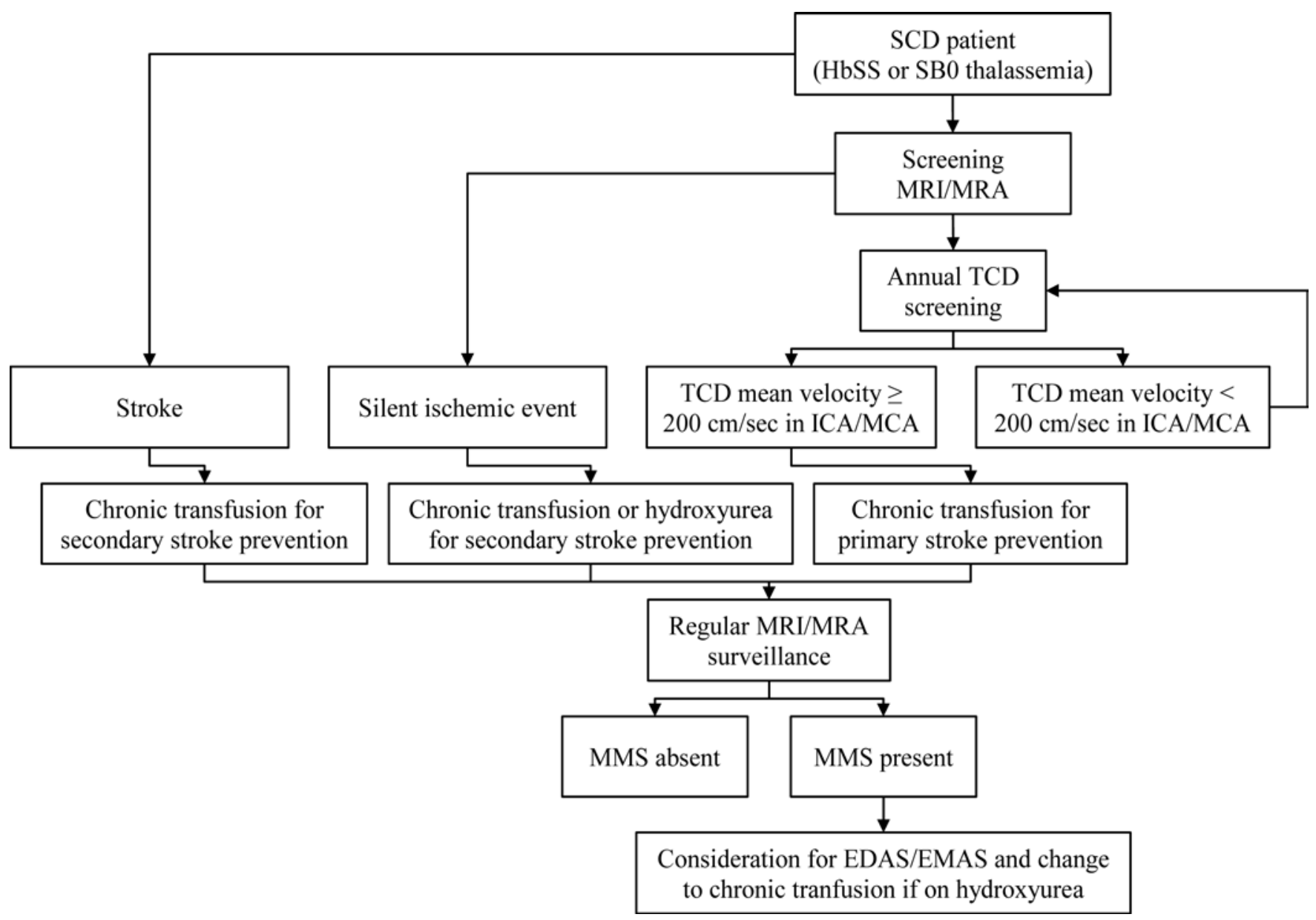

FIG. 1. Institutional protocol for the management of stroke prevention in patients with $\mathrm{SCD}$. $\mathrm{HbSS}=\mathrm{HbS}$; $\mathrm{SBO}=$ sickle cell/ $\beta$ thalassemia.

The children were maintained in the intensive care unit overnight with careful attention to hydration and pain control and then were transferred to the floor the following day on 1.5-times maintenance fluids. Preoperative and followup MRA and/or DSA were assessed for arterial stenosis, arterial occlusion, graft patency, and neovascularization.

\section{Statistical Analysis}

Statistical analysis was performed using $\mathrm{R}$ version 3.1.1 (http://www.r-project.org). Categorical variables were compared between groups by the Fisher exact test. Numerical variables were compared between groups by ANOVA. A $p$ value of $<0.05$ was considered statistically significant.

Pairwise comparison as a follow-up to ANOVA was performed for time and $\mathrm{Hb}$ and $\mathrm{HbS}$ levels on transfusion therapy using t-tests. A p value of $<0.00278$ was considered statistically significant using the Bonferroni correction for 18 comparisons $\left(\alpha^{*}=\alpha / \mathrm{K}=0.05 / 18=0.00278\right)$ (Table 1).

\section{Results}

A total of 62 patients with SCD and on chronic transfusion therapy were included. After exclusion of patients with an indication for chronic transfusion therapy other than stroke prevention, 48 patients $(77.4 \%)$ remained. Of those patients, 14 (29.2\%) underwent EDAS or EMAS. Nine $(18.8 \%)$ and $25(52.1 \%)$ patients were on chronic transfusion therapy for primary or secondary stroke prevention, respectively, but did not undergo EDAS or EMAS (Table 1).

\section{Patients With SCD on Chronic Transfusion Therapy for Primary or Secondary Stroke Prevention}

Thirty-four patients were on chronic transfusion therapy for primary or secondary stroke prevention but did not undergo EDAS or EMAS. The mean ages of those patients were $11.5 \pm 4.9$ and $14.1 \pm 6.0$ years, respectively, and did not differ from that of the patients who underwent EDAS or EMAS ( $p=0.277)$. MMS was present in $22.2 \%$ and $24.0 \%$ of the patients, respectively, and was present significantly less frequently than in the patients who underwent EDAS or EMAS ( $<$ 0.0001). Pairwise comparison for $\mathrm{Hb}$ levels between groups did not affirm the statistical significance detected with ANOVA. HbS levels in patients on chronic transfusion therapy for primary and secondary stroke prevention compared less favorably than that in patients who underwent EDAS or EMAS, as evidenced 
TABLE 1. All patients on transfusion therapy for stroke prevention, including those who underwent EDAS or EMAS

\begin{tabular}{|c|c|c|c|c|c|c|}
\hline \multirow[b]{2}{*}{ Characteristic } & \multirow[b]{2}{*}{$\begin{array}{l}\text { All Patients } \\
\qquad(\mathrm{n}=48)\end{array}$} & \multicolumn{2}{|c|}{ Patients on Transfusion Therapy $(n=34)$} & \multicolumn{2}{|c|}{$\begin{array}{l}\text { Patients Who Underwent } \\
\text { EDAS/EMAS }(n=14)\end{array}$} & \multirow[b]{2}{*}{$\begin{array}{c}\mathrm{p} \\
\text { Value }\end{array}$} \\
\hline & & $\begin{array}{c}\text { For Primary } \\
\text { Stroke Prevention } \\
\qquad(n=9)\end{array}$ & $\begin{array}{l}\text { For Secondary } \\
\text { Stroke Prevention } \\
\qquad(n=25)\end{array}$ & $\begin{array}{l}\text { Before EDAS/ } \\
\text { EMAS }\end{array}$ & $\begin{array}{l}\text { After EDAS/ } \\
\text { EMAS }\end{array}$ & \\
\hline \multicolumn{7}{|l|}{ Demographics } \\
\hline Age (mean \pm SD) (yrs) & $14.0 \pm 5.7$ & $11.5 \pm 4.9$ & $14.1 \pm 6.0$ & \multicolumn{2}{|c|}{$15.3 \pm 5.3$} & 0.277 \\
\hline Sex (no. [\%]) & & & & & & 0.243 \\
\hline Male & $20(41.7)$ & $6(66.7)$ & $9(36.0)$ & \multicolumn{2}{|c|}{$5(35.7)$} & \\
\hline Female & $28(58.3)$ & $3(33.3)$ & $16(64.0)$ & \multicolumn{2}{|c|}{$9(64.3)$} & \\
\hline \multicolumn{7}{|l|}{ Imaging results (no. [\%]) } \\
\hline $\begin{array}{l}\text { Initiation of chronic transfusion therapy } \\
\text { after TCD screening }\end{array}$ & $16(33.3)$ & $9(100)$ & $0(0)$ & \multicolumn{2}{|c|}{$7(50)$} & $<0.0001$ \\
\hline Presence of MMS & $22(45.8)$ & $2(22.2)$ & $6(24.0)$ & \multicolumn{2}{|c|}{$14(100)$} & $<0.0001$ \\
\hline \multicolumn{7}{|l|}{ Chronic transfusion therapy } \\
\hline $\begin{array}{l}\text { Time on transfusion therapy (mean } \pm \\
\text { SD) (mos) }\end{array}$ & $102.8 \pm 62.4$ & $85.8 \pm 54.4$ & $104.6 \pm 67.7$ & $76.8 \pm 58.8$ & $33.7 \pm 19.6$ & 0.00477 \\
\hline $\begin{array}{l}\text { Hb level on chronic transfusion therapy } \\
\quad(\text { mean } \pm \mathrm{SD})(\mathrm{g} / \mathrm{dl})\end{array}$ & $9.3 \pm 0.8$ & $9.1 \pm 0.6$ & $9.1 \pm 0.9$ & $9.4 \pm 0.4$ & $9.9 \pm 0.7$ & 0.00912 \\
\hline $\begin{array}{l}\text { HbS level on chronic transfusion thera- } \\
\text { py (mean } \pm \mathrm{SD})(\%)\end{array}$ & $33.9 \pm 10.7$ & $42.4 \pm 12$ & $34.3 \pm 10.8$ & $29.5 \pm 6.4$ & $25.5 \pm 6.1$ & $<0.0001$ \\
\hline
\end{tabular}

by mean $\mathrm{HbS}$ levels of $42.4 \% \pm 12 \%$ and $34.3 \% \pm 10.8 \%$, respectively $(p<0.0001)$. This result was reaffirmed by pairwise comparison, which revealed that patients on chronic transfusion therapy for both primary and secondary stroke prevention had significantly higher HbS levels than patients after EDAS or EMAS ( $p=0.00176$ and 0.00255 , respectively).

\section{Patients With SCD and on Chronic Transfusion Therapy After EDAS/EMAS \\ Preoperative Course}

A total of 14 patients (5 male and 9 female) with a mean age of $15.3 \pm 5.3$ years at the time of surgery underwent EMAS or EDAS (Table 2). The most common indication for the initial cerebrovascular imaging was screening (50\% of patients), and the second most common indication was stroke $(28.6 \%)$. The mean time from initiation of chronic transfusion therapy to EDAS/EMAS was $76.8 \pm 58.8$ months. Progressive vascular disease $(92.9 \%)$ and history of stroke $(71.4 \%)$ were the most common indications for EDAS/EMAS. Ten strokes occurred in 78.1 patient-years (total number of years that patients were followed before EDAS/EMAS) before EDAS/EMAS, which resulted in a calculated stroke rate of 1 per 7.8 patient-years. All patients were on chronic transfusion therapy and had a mean $\mathrm{Hb}$ level of $9.4 \pm 0.4 \mathrm{~g} / \mathrm{dl}$ and a mean HbS level of $29.5 \%$ $\pm 6.4 \%$.

\section{Radiographic Features}

Preoperative MRI and MRA for all the patients were available for review. Each of the 10 patients who had a stroke before EDAS had correlating ischemic changes shown in MRI. The 4 patients without a stroke before
EDAS also had evidence of ischemic events on MRI. During the pre-EDAS/EMAS period, there were 10 ischemic events in 9 patients $(64.3 \%)$ that remained clinically silent. For 7 patients who each had bilateral MMS, preEDAS/EMAS DSA studies were available and reviewed. The median Suzuki grade ${ }^{33}$ was 4 (range 3-5) (Table 2). Bilateral progressive vascular disease was present in 12 $(85.7 \%)$ of the 14 patients. Ten $(71.4 \%)$ of the 14 patients had bilateral ischemic changes, as revealed in MRI.

\section{Surgical Technique}

Information on the surgeries and outcomes is presented in Table 3. In Patients 1-6, the donor scalp artery, most commonly the posterior branch of the superficial temporal artery, was transposed with a small muscle cuff still attached (EMAS ${ }^{25}$ ). In the remainder of the patients, the technical aspects of EDAS were performed as previously described. ${ }^{17}$ Dural inversion in addition to EDAS or EMAS was performed in $5(23.8 \%)$ of 21 procedures. Perioperative management was similar to that in previously reported series. ${ }^{17}$

\section{Perioperative Complications}

Transient nonspecific slowing was noted in all the patients who underwent intraoperative electroencephalography, with focal changes in several patients that did not correlate with postoperative deficit or seizures. Complications occurred in 4 different patients, with 1 stroke 2 weeks after surgery, 1 perioperative seizure, 1 symptomatic subdural hygroma (headaches) that required bur hole drainage, and 1 case of intraoperative cerebral edema that precluded replacement of the bone flap. In Patient 1, who suffered a stroke 2 weeks after surgery, MRI revealed new ischemic changes in the left frontoparietal region, and the child re- 


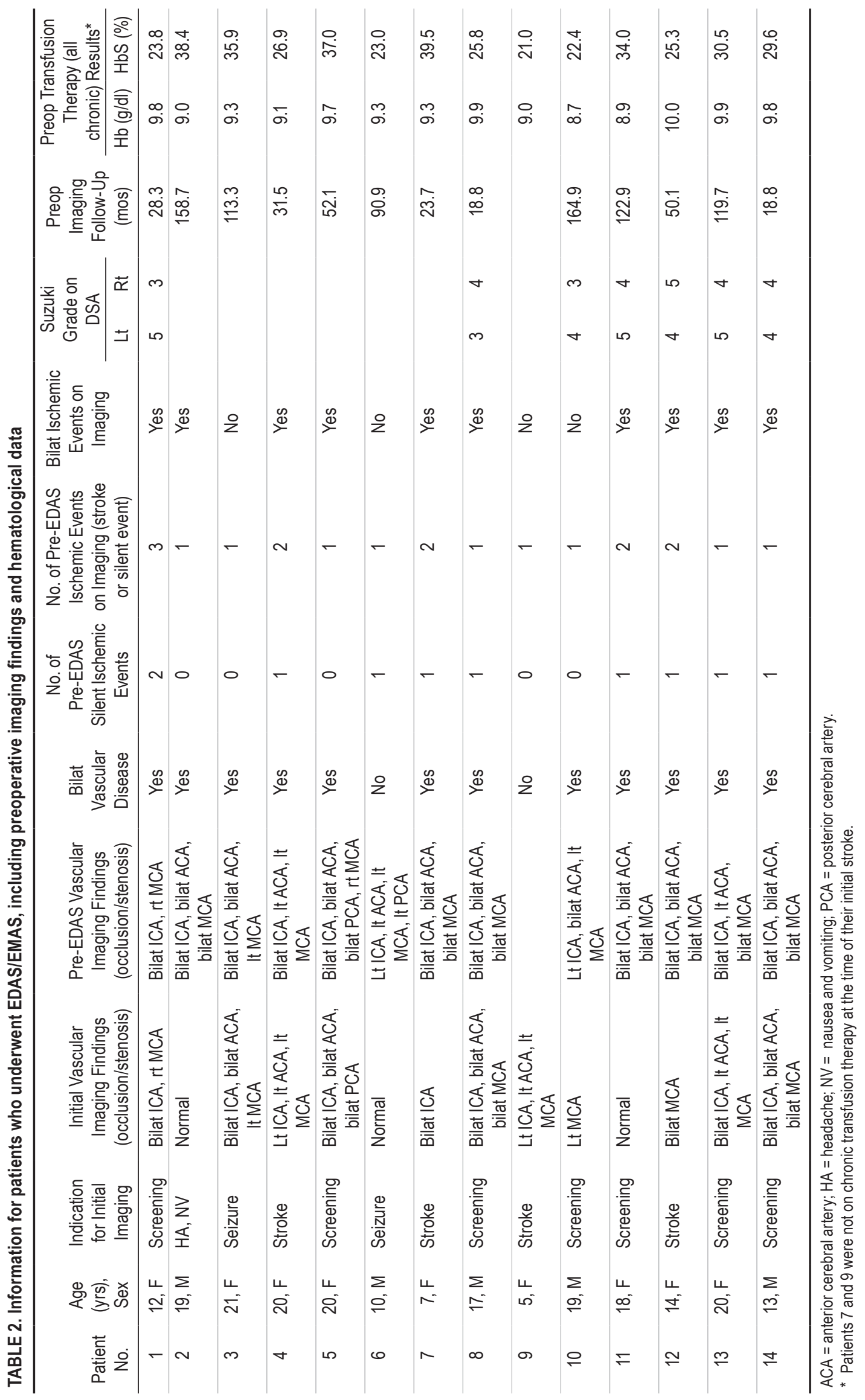




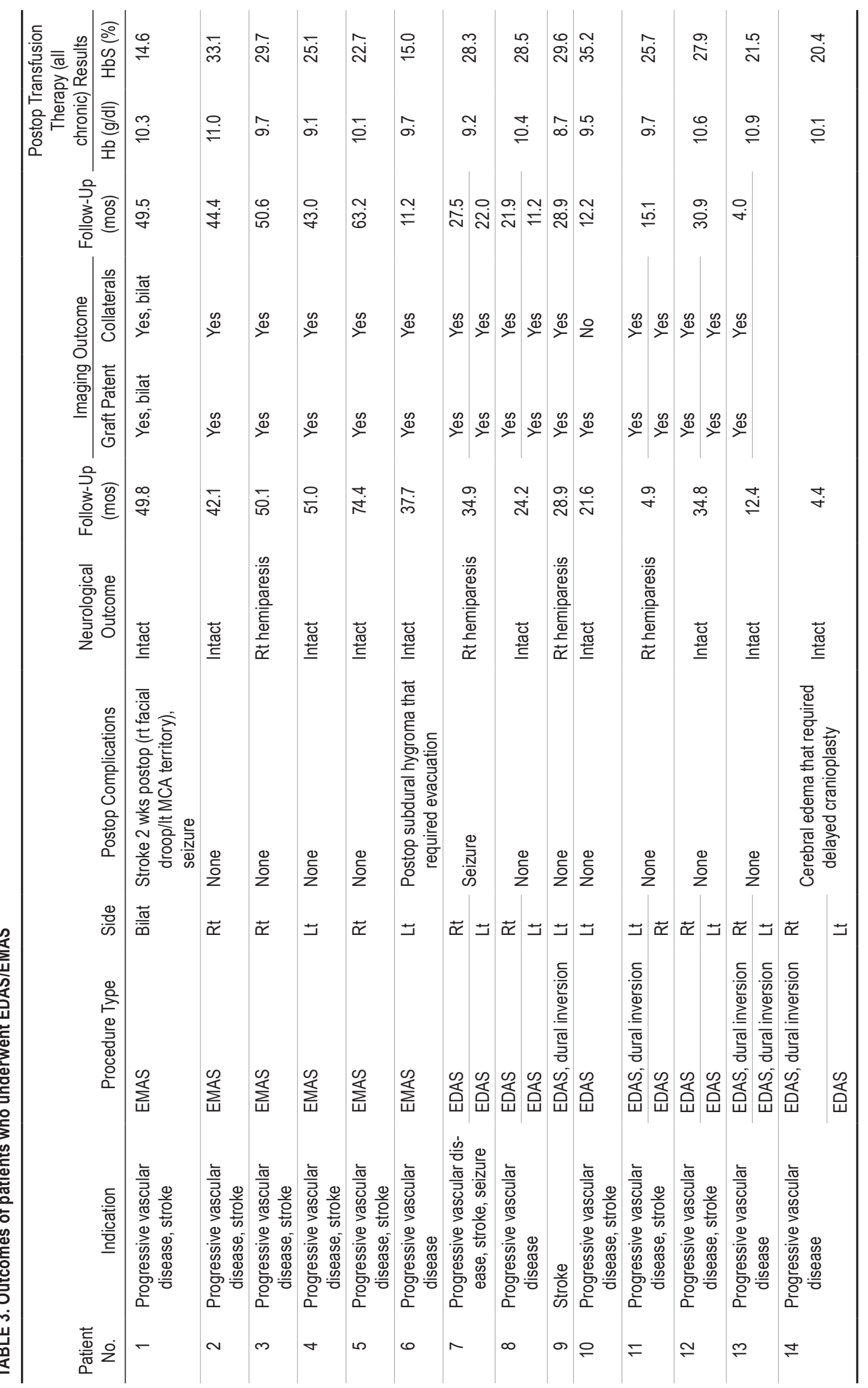


turned to neurological baseline without permanent deficit. None of the other complications resulted in a transient or permanent neurological deficit. There were no deaths in the cohort.

\section{Radiographic Outcome}

All of the patients in the present series with radiological follow-up had a patent graft. Of the hemispheres on which surgery was performed, all but one (93.8\%) showed radiological evidence of collateral formation at the last follow-up. No differences were noted between the patients who underwent dural inversion and those who did not. Radiological follow-up was obtained routinely via MRA to eliminate risks associated with DSA.

\section{Clinical Outcome After Discharge}

Other than in Patient 1, no additional strokes occurred during the clinical follow-up period (mean $33.7 \pm 19.6$ months). One stroke in 39.3 patient-years (total number of years patients were followed after EDAS/EMAS) after EDAS/EMAS resulted in a post-EDAS/EMAS stroke rate of 1 stroke per 39.3 patient-years, a 5-fold reduction in that of the pre-EDAS/EMAS period (1 stroke per 7.8 patientyears). Likewise, no additional ischemic events occurred. At the last follow-up, 10 (71.4\%) of 14 patients were neurologically intact. Four patients (28.6\%) suffered from persistent hemiparesis from their initial stroke (Table 3). The mean post-EDAS/EMAS HbS level was $25.5 \% \pm 6.1 \%$, not significantly different from that in the pre-EDAS/EMAS period $(\mathrm{p}=0.104)$.

\section{Discussion}

In this study, we compared all pediatric patients with SCD and on chronic transfusion therapy for stroke prevention to patients who underwent EDAS or EMAS. Patients with SCD have an approximately 250-times-higher risk of stroke than the general childhood population..$^{10}$ Chronic transfusion therapy is the mainstay treatment for primary and secondary neurovascular complications..$^{2,3,12,22,30,35}$ Although chronic transfusion therapy prevents initial and recurrent stroke in the majority of patients, some patients on chronic transfusion therapy continue to experience strokes and develop progressive vascular disease..$^{19,30}$ The progression of their vascular disease triggers the development of a fragile network of arteries that resembles MMD and is present in 30\%-43\% of patients with SCD and a history of stroke. ${ }^{13,31}$ In our study, $45.8 \%$ of the patients on chronic transfusion therapy had MMS. These patients in particular are at a high risk for strokes despite optimal medical therapy. ${ }^{32}$ This higher failure rate of chronic transfusion therapy in patients with SCD and MMS warrants the evaluation of supplemental alternative treatments. EDAS or EMAS with pial synangiosis, an indirect bypass procedure aimed at revascularizing the ischemic brain, was first performed in a patient with SCD in $1996^{34}$ and has since been reported from small case series in other centers. ${ }^{15,17,21,34}$ A comparison of stroke rates before and after EDAS/EMAS revealed a significant reduction after the procedure. Results from our experience with indirect revascularization in 14 patients with SCD and MMS are consistent with those in these other series, with a similar complication rate and apparent improvement in overall stroke risk as measured by the number of strokes per patient-year. However, the majority of our patients did not undergo revascularization for years after their initial stroke and did not experience a second stroke during that waiting period. This relatively benign natural history, at least in terms of clinically diagnosed stroke, makes interpretation of the total stroke risk reduction (i.e., strokes per patient-year) after EDAS/ EMAS for children with SCD much more problematic, especially after short a follow-up period.

\section{Medical Management of MMS in Patients With SCD}

The neurological sequelae of SCD include but are not limited to transient ischemic attack, stroke, hemorrhage, seizure, and decline in neurocognitive function and are associated with significant morbidity and death. Before TCD screening for stroke risk, approximately $10 \%$ of all children with SCD suffered a stroke, and recurrence rates ranged from $46 \%$ to $90 \%$ in patients who did not receive any secondary stroke-prevention therapy. ${ }^{1}$ Chronic transfusion therapy reduces stroke recurrence rates to approximately $10 \%{ }^{31}$ to $20 \%{ }^{19}$ and provides a $90 \%$ reduction in the rate of first stroke in patients at high risk as determined by increased blood-flow velocities on TCD. ${ }^{5}$ Patients at high risk have TCD velocities of the terminal ICA and MCA of $\geq 200 \mathrm{~cm} / \mathrm{sec}^{5}$ The Stroke Prevention Trial in Sickle Cell Anemia (STOP) was a landmark prospective randomized stroke-prevention trial in patients with SCD at high risk for stroke; it found chronic transfusion therapy with a goal $\mathrm{HbS}$ level of $\leq 30 \%$ to be associated with a significant reduction in stroke risk, which led to early termination of the trial. ${ }^{2}$ However, chronic transfusion therapy for primary or secondary stroke prevention carries notable adverse effects, including iron overload and alloimmunization. In addition, chronic transfusion therapy is known to be less effective in patients who have developed MMS. ${ }^{21}$ Recent work showed that patients with SCD and MMS on chronic transfusion therapy with the identical $\mathrm{HbS}$ goal of $30 \%$ are twice as likely to incur recurrent strokes than are patients with SCD without MMS. ${ }^{13}$

In our study, $18.8 \%$ of the patients were found to have a mean TCD velocity of $\geq 200 \mathrm{~cm} / \mathrm{sec}$ and were placed on chronic transfusion therapy for primary stroke prevention. Fifty-two percent of the patients presented with a stroke or silent ischemic event and received chronic transfusion therapy for secondary stroke prevention. HbS levels in those patients were in the range of $42.4 \% \pm 12 \%$ and $34.3 \% \pm 10.8 \%$, respectively, and compared less favorably to the levels of patients who underwent EDAS or EMAS and were more adequately managed on chronic transfusion therapy, as evidenced by mean HbS levels of $29.5 \%$ $\pm 6.4 \%$ and $25.5 \% \pm 6.1 \%$ before and after EDAS/EMAS, respectively. Overall, the findings compare well to those of current chronic transfusion practice in patients with SCD, which were surveyed in a recent study that found an average pretransfusion $\mathrm{HbS}$ level of $35 \% \pm 11 \% .^{6}$ When data from our patients with MMS after EDAS or EMAS were combined with those of patients from previous studies, $21(47.7 \%)$ of 44 patients had suffered a stroke on chronic transfusion therapy. Two patients (Patients 7 and 9) in our 
series had their initial stroke while off transfusion therapy and were subsequently placed on it for secondary stroke prevention. It is unfortunate that previous studies did not include $\mathrm{HbS}$ data to demonstrate the adequacy of chronic transfusion therapy in their patients. Nevertheless, this number is comparable to the stroke rate of $58 \%$ in patients with MMS on chronic transfusion therapy reported previously. ${ }^{13}$ Whether chronic transfusion therapy slows the progression of vascular disease and prevents involvement of the contralateral hemisphere in patients with unilateral disease is uncertain..$^{21}$ Contrary to an observation made in a previous study, ${ }^{21} 2$ (Patients 4 and 10) of 3 patients (Patients 4, 6, and 10) in our series with unilateral disease seen on initial imaging progressed and developed contralateral MMS before EDAS/EMAS. With pre-EDAS/ EMAS HbS levels of $26.9 \%, 23.0 \%$, and $22.4 \%$, respectively, their $\mathrm{HbS}$ levels were equally well controlled.

Historically, our institution has not recommended aspirin for stroke prevention in children with SCD and MMS because of bleeding concerns in a young adult population that has a known increased risk of hemorrhagic stroke. ${ }^{29}$ Although a recent single-center retrospective review suggested the safety and benefit of aspirin in this population, ${ }^{23}$ we feel that a prospective randomized trial is required before recommending aspirin for the prevention of stroke in children with SCD and MMS.

\section{Surgical Management of MMS in Patients With SCD}

EDAS was first reported in $1981^{24}$ as a surgical treatment for MMD in the Asian population and has become the preferred technique for indirect revascularization in patients with SCD. The technique requires the exposure and dissection of a branch of the superficial temporal artery, usually the parietal branch, with preservation of flow throughout the entirety of the procedure. Once the artery is isolated, it is mobilized, and a craniotomy overlying the sylvian fissure is performed. The arachnoid is opened extensively, and the superficial temporal artery branch is tagged to the pia of the cortical surface. Variations in the procedure have been reported and include EMAS, in which the donor artery is transposed with a small muscle cuff still attached. Other variations include encephalomyosynangiosis, ${ }^{25}$ the addition of bur holes, ${ }^{14,20}$ inversion of the dura, ${ }^{11}$ or a combination of the aforementioned procedures. ${ }^{25}$ Dural inversion is performed in hopes that the middle meningeal artery circulation that richly vascularizes the outer dural surface will serve as a source of collateral formation once brought into contact with the cortical surface. ${ }^{11}$ In our series, EMAS was performed on 7 hemispheres (Patients 1-6), and the remainder of the patients underwent EDAS with or without dural inversion. The complication rates for EMAS and EDAS were $28.6 \%$ (Patients 1 and 6) and $14.3 \%$ of hemispheres (Patients 7 and 14), respectively, with 1 transient neurological deficit in a child who suffered a stroke 2 weeks after EMAS.

All the patients in our series with radiological followup had a patent graft. Consistent with observations from other series, despite progressive intracranial vascular disease, the graft remained patent after EDAS/EMAS. ${ }^{17,21}$ Of the hemispheres on which surgery was performed, all but $1(93.8 \%)$ showed radiological evidence of collateral for- mation at the last follow-up, which is consistent with the existing literature in which $87 \%$ of hemispheres on which surgery was performed demonstrated arterial ingrowth. ${ }^{21}$ Radiological follow-up was obtained routinely via MRA in the majority of cases to eliminate risks associated with DSA.

In the pediatric population, indirect revascularization has several advantages over direct revascularization (i.e., superficial temporal artery-to-MCA bypass). Direct bypass is technically challenging in the pediatric population because of the smaller diameter of the arteries and has been associated with symptomatic hyperperfusion, particularly in patients with MMS, ${ }^{16}$ and perioperative ischemic events during temporary artery occlusion, which is necessary when performing the anastomosis. ${ }^{21}$ The progression of vascular disease in patients with MMS may be accelerated with direct bypass. ${ }^{18}$ Compared with direct bypass, perioperative complications with EDAS/EMAS occur less frequently, because the procedure is less technically challenging, temporary artery occlusion is not required, and symptomatic hyperperfusion does not occur because it does not rely on a direct arterial anastomosis. The rate of nonneurological complications such as wound infections or pseudomeningocele was $11 \%$ in another series. ${ }^{21}$ No nonneurological complications occurred in our study.

\section{Stroke Prevention in Patients With SCD and MMS After EDAS}

Combining our experience with that in previously published series reports in which indirect revascularization for MMS and SCD was evaluated, a total of 69 EDAS/EMAS procedures were performed in 44 patients. ${ }^{21,32,34}$ Threefourths of all patients combined had an ischemic stroke before EDAS/EMAS, and no patient presented with intracranial hemorrhage. Forty-seven percent of the patients had a stroke while on chronic transfusion therapy. In our study, there was 1 stroke per 7.8 patient-years during the pre-EDAS/EMAS follow-up period. After EDAS/EMAS, the rate dropped to 1 stroke per 39.3 patient-years, a 5-fold reduction of that in the pre-EDAS/EMAS period. These results are strikingly similar to the changes in stroke rates observed in all previous case series combined. ${ }^{21,32,34}$ There, the stroke rate dropped from 1 stroke per 13 patient-years before EDAS/EMAS to 1 stroke per 81 patient-years after EDAS/EMAS, a 6-fold decrease. ${ }^{21}$ This stroke reduction included 10 clinically silent ischemic events that occurred in 9 patients $(64.3 \%)$ in the present study. Silent events are reported in $27.5 \%$ of patients with SCD and MMS on chronic transfusion therapy. ${ }^{19}$ Although these events do not necessarily manifest as clinically diagnosed strokes (i.e., hemiparesis, aphasia, etc.), they may be associated with progressive cognitive decline.

SCD is most prevalent in African Americans and Hispanics but can occur in people of all races. It is estimated that approximately 1 in 500 African American babies born in the United States has the disease. ${ }^{9}$ In the Nationwide Inpatient Sample database, there were 2,024 hospitalizations for stroke identified from 1993 to 2009, approximately $0.4 \%$ of all hospitalizations for pediatric patients with SCD. The mean annual incidence rate of hospitalization for stroke in pediatric patients with SCD during 
the years 1999-2009 had decreased by 45\% compared with the incidence from 1993 to 1998. Publication of the STOP results and the use of hydroxyurea are possible reasons for the decrease in stroke hospitalizations. ${ }^{26}$ Of the 62 patients currently on chronic transfusion therapy at our institution, $18.8 \%$ and $52.1 \%$ of the patients are treated for primary or secondary stroke prevention, respectively. Despite the relatively high prevalence of pediatric SCD and use of chronic transfusion therapy for stroke prevention, EDAS/EMAS seems to be performed relatively infrequently to prevent stroke in patients with SCD. Only 69 EDAS/EMAS procedures in 44 patients have been reported in a highly selected group of patients with SCD. ${ }^{17,21,32,34}$ Of the 6 patients with MMS in our study who were on chronic transfusion therapy for secondary stroke prevention, 2 were offered EDAS/ EMAS but declined. Compliance and adherence to chronic transfusion therapy is paramount for the selection of patients with MMS for EDAS/EMAS. Here, patients who did not undergo EDAS/EMAS were significantly less well controlled on chronic transfusion therapy, as evidenced by their higher $\mathrm{HbS}$ levels, which made them less favorable candidates for these procedures.

\section{Limitations}

The most important limitation of this and other studies $^{17,21,32}$ lies in the potentially flawed study design. Like the study presented here, previous studies have used pre-EDAS/EMAS stroke rates and compared them to post-EDAS/EMAS stroke rates as their main end point. Although the magnitude of the drop in the post-EDAS/ EMAS stroke rate was remarkable in our and other studies, no study has directly compared EDAS/EMAS to the best nonsurgical therapy. Given the long interval between first stroke and surgical revascularization in our study, the natural history of SCD with MMS may be less malignant than in classic MMD. It is our experience that, although most of these children have not had another clinically diagnosed stroke after their initial event, the majority of them have experienced significant cognitive decline, development of headache syndromes, and other behavioral disturbances. Whether these changes are a result of microvascular or macrovascular events (and thus are treatable by EDAS/EMAS) is unclear. The high rate of silent ischemic events (64\% of patients) visualized on MRI in this series, however, may account for at least some of the cognitive decline. Future studies clearly need more subtle outcome measures, including but not limited to cognitive performance, patient symptom scores, and quantitative MRI/ MRA to adequately substantiate the efficacy of EDAS/ EMAS for improving the lives of children with SCD and MMS. Using these end points, a randomized prospective multicenter trial is needed to more definitively determine the efficacy of EDAS/EMAS as an adjunct to standard transfusion therapy in the management of children with this challenging disease.

\section{Conclusions}

The results of this study, consistent with those from other centers, suggest that indirect revascularization in pediatric patients with SCD and MMS is safe and may result in a significant reduction of stroke risk in these patients. However, drawing widespread conclusions from the study design is problematic given the unclear natural history of the disease, limitations of stroke as an outcome measure, and the lack of true randomized comparison with nonsurgical therapy only. Given these limitations and the relative rarity of children with SCD and MMS, a definitive, prospective, multicenter trial that evaluates the efficacy of EDAS/EMAS as an adjunct to transfusion therapy for preventing stroke and other cognitive sequelae is warranted.

\section{Acknowledgment}

We acknowledge Michael R. DeBaun, MD, MPH, Department of Pediatric Hematology Oncology, Monroe Carell Jr. Children's Hospital at Vanderbilt (Nashville, TN), for his assistance with this project.

\section{References}

1. Adams RJ, McKie VC, Brambilla D, Carl E, Gallagher D, Nichols FT, et al: Stroke prevention trial in sickle cell anemia. Control Clin Trials 19:110-129, 1998

2. Adams RJ, McKie VC, Hsu L, Files B, Vichinsky E, Pegelow $\mathrm{C}$, et al: Prevention of a first stroke by transfusions in children with sickle cell anemia and abnormal results on transcranial Doppler ultrasonography. N Engl J Med 339:5-11, 1998

3. Adams RJ, Brambilla D, Optimizing Primary Stroke Prevention in Sickle Cell Anemia (STOP 2) Trial Investigators: Discontinuing prophylactic transfusions used to prevent stroke in sickle cell disease. N Engl J Med 353:2769-2778, 2005

4. Adelson PD, Scott RM: Pial synangiosis for moyamoya syndrome in children. Pediatr Neurosurg 23:26-33, 1995

5. Arkuszewski M, Krejza J, Chen R, Ichord R, Kwiatkowski JL, Bilello M, et al: Sickle cell anemia: intracranial stenosis and silent cerebral infarcts in children with low risk of stroke. Adv Med Sci 59:108-113, 2014

6. Aygun B, McMurray MA, Schultz WH, Kwiatkowski JL, Hilliard L, Alvarez O, et al: Chronic transfusion practice for children with sickle cell anaemia and stroke. Br J Haematol 145:524-528, 2009

7. Bishop S, Matheus MG, Abboud MR, Cane ID, Adams RJ, Jackson SM, et al: Effect of chronic transfusion therapy on progression of neurovascular pathology in pediatric patients with sickle cell anemia. Blood Cells Mol Dis 47:125-128, 2011

8. Brousse V, Hertz-Pannier L, Consigny Y, Bresson JL, Girot $\mathrm{R}$, Mirre E, et al: Does regular blood transfusion prevent progression of cerebrovascular lesions in children with sickle cell disease? Ann Hematol 88:785-788, 2009

9. Centers for Disease Control and Prevention: Sickle Cell Disease (SCD): Data \& Statistics. (http://www.cdc.gov/ ncbddd/sicklecell/data.html) [Accessed February 19, 2015]

10. Cherry MG, Greenhalgh J, Osipenko L, Venkatachalam M, Boland A, Dundar Y, et al: The clinical effectiveness and cost-effectiveness of primary stroke prevention in children with sickle cell disease: a systematic review and economic evaluation. Health Technol Assess 16:1-129, 2012

11. Dauser RC, Tuite GF, McCluggage CW: Dural inversion procedure for moyamoya disease. Technical note. J Neurosurg 86:719-723, 1997

12. DeBaun MR, Gordon M, McKinstry RC, Noetzel MJ, White DA, Sarnaik SA, et al: Controlled trial of transfusions for silent cerebral infarcts in sickle cell anemia. N Engl J Med 371:699-710, 2014

13. Dobson SR, Holden KR, Nietert PJ, Cure JK, Laver JH, 
Disco D, et al: Moyamoya syndrome in childhood sickle cell disease: a predictive factor for recurrent cerebrovascular events. Blood 99:3144-3150, 2002

14. Dusick JR, Gonzalez NR, Martin NA: Clinical and angiographic outcomes from indirect revascularization surgery for Moyamoya disease in adults and children: a review of 63 procedures. Neurosurgery 68:34-43, 2011

15. Fryer RH, Anderson RC, Chiriboga CA, Feldstein NA: Sickle cell anemia with moyamoya disease: outcomes after EDAS procedure. Pediatr Neurol 29:124-130, 2003

16. Fujimura M, Shimizu H, Inoue T, Mugikura S, Saito A, Tominaga T: Significance of focal cerebral hyperperfusion as a cause of transient neurologic deterioration after extracranial-intracranial bypass for moyamoya disease: comparative study with non-moyamoya patients using $\mathrm{N}$-isopropyl-p-[(123)I]iodoamphetamine single-photon emission computed tomography. Neurosurgery 68:957-965, 2011

17. Hankinson TC, Bohman LE, Heyer G, Licursi M, Ghatan S, Feldstein NA, et al: Surgical treatment of moyamoya syndrome in patients with sickle cell anemia: outcome following encephaloduroarteriosynangiosis. J Neurosurg Pediatr 1:211-216, 2008

18. Houkin K, Nakayama N, Kuroda S, Ishikawa T, Nonaka T: How does angiogenesis develop in pediatric moyamoya disease after surgery? A prospective study with MR angiography. Childs Nerv Syst 20:734-741, 2004

19. Hulbert ML, McKinstry RC, Lacey JL, Moran CJ, Panepinto JA, Thompson AA, et al: Silent cerebral infarcts occur despite regular blood transfusion therapy after first strokes in children with sickle cell disease. Blood 117:772-779, 2011

20. Kapu R, Symss NP, Cugati G, Pande A, Vasudevan CM, Ramamurthi R: Multiple burr hole surgery as a treatment modality for pediatric moyamoya disease. J Pediatr Neurosci 5:115-120, 2010

21. Kennedy BC, McDowell MM, Yang PH, Wilson CM, Li S, Hankinson TC, et al: Pial synangiosis for moyamoya syndrome in children with sickle cell anemia: a comprehensive review of reported cases. Neurosurg Focus 36(1):E12, 2014

22. Lee MT, Piomelli S, Granger S, Miller ST, Harkness S, Brambilla DJ, et al: Stroke Prevention Trial in Sickle Cell Anemia (STOP): extended follow-up and final results. Blood 108:847-852, 2006

23. Majumdar S, Miller M, Khan M, Gordon C, Forsythe A, Smith MG, et al: Outcome of overt stroke in sickle cell anaemia, a single institution's experience. Br J Haematol 165:707-713, 2014

24. Matsushima Y, Fukai N, Tanaka K, Tsuruoka S, Inaba Y, Aoyagi M, et al: A new surgical treatment of moyamoya disease in children: a preliminary report. Surg Neurol 15:313320, 1981

25. Matsushima T, Inoue T, Katsuta T, Natori Y, Suzuki S, Ikezaki K, et al: An indirect revascularization method in the surgical treatment of moyamoya disease-various kinds of indirect procedures and a multiple combined indirect procedure. Neurol Med Chir (Tokyo) 38 (Suppl):297-302, 1998
26. McCavit TL, Xuan L, Zhang S, Flores G, Quinn CT: National trends in incidence rates of hospitalization for stroke in children with sickle cell disease. Pediatr Blood Cancer 60:823827,2013

27. Moran CJ, Siegel MJ, DeBaun MR: Sickle cell disease: imaging of cerebrovascular complications. Radiology 206:311321, 1998

28. Moritani T, Numaguchi Y, Lemer NB, Rozans MK, Robinson AE, Hiwatashi A, et al: Sickle cell cerebrovascular disease: usual and unusual findings on MR imaging and MR angiography. Clin Imaging 28:173-186, 2004

29. Ohene-Frempong K, Weiner SJ, Sleeper LA, Miller ST, Embury S, Moohr JW, et al: Cerebrovascular accidents in sickle cell disease: rates and risk factors. Blood 91:288-294, 1998

30. Pegelow CH, Adams RJ, McKie V, Abboud M, Berman B, Miller ST, et al: Risk of recurrent stroke in patients with sickle cell disease treated with erythrocyte transfusions. J Pediatr 126:896-899, 1995

31. Russell MO, Goldberg HI, Hodson A, Kim HC, Halus J, Reivich M, et al: Effect of transfusion therapy on arteriographic abnormalities and on recurrence of stroke in sickle cell disease. Blood 63:162-169, 1984

32. Smith ER, McClain CD, Heeney M, Scott RM: Pial synangiosis in patients with moyamoya syndrome and sickle cell anemia: perioperative management and surgical outcome. Neurosurg Focus 26(4):E10, 2009

33. Suzuki J, Takaku A: Cerebrovascular "moyamoya" disease. Disease showing abnormal net-like vessels in base of brain. Arch Neurol 20:288-299, 1969

34. Vernet O, Montes JL, O'Gorman AM, Baruchel S, Farmer JP: Encephaloduroarterio-synangiosis in a child with sickle cell anemia and moyamoya disease. Pediatr Neurol 14:226230, 1996

35. Ware RE, Helms RW, SWiTCH Investigators: Stroke With Transfusions Changing to Hydroxyurea (SWiTCH). Blood 119:3925-3932, 2012

\section{Author Contributions}

Conception and design: Johnston, Griessenauer, Bemrich-Stolz, Howard. Acquisition of data: Griessenauer, Lebensburger, Bemrich-Stolz. Analysis and interpretation of data: Johnston, Griessenauer, Lebensburger, Chua. Drafting the article: Griessenauer, Lebensburger. Critically revising the article: Johnston, Griessenauer, Lebensburger, Fisher, Hilliard. Reviewed submitted version of manuscript: Johnston, Griessenauer, Lebensburger, Fisher, Hilliard. Statistical analysis: Griessenauer, Chua. Administrative/technical/material support: Johnston, Griessenauer. Study supervision: Johnston, Griessenauer.

\section{Correspondence}

James M. Johnston, 1530 3rd Ave. S, Birmingham, AL 35209. email: james.johnston@childrensal.org. 